\title{
Flight Range Extension of a Guided Aerial Bomb with a Rocket Engine during Climb Bombing
}

\author{
I.S. Kravchuk ${ }^{1}$, V.V. Taranenko ${ }^{2}$, D.V. Bashynskyi ${ }^{2 *}$ and M.V. Zirka ${ }^{3}$ \\ ${ }^{1}$ Research \& Development Company "Adron”, Kyiv, Ukraine \\ ${ }^{2}$ State Research Institute of Aviation, Kyiv, Ukraine \\ ${ }^{3}$ Researcher of the Central Research Institute of Armament and Military Equipment \\ of Armed Forces of Ukraine, Kyiv, Ukraine
}

The manuscript was received on 2 December 2020 and was accepted after revision for publication as research paper on 28 September 2021.

\begin{abstract}
:
The possibility of a significant flight range extension of a guided aerial bomb during climb bombing due to the jet thrust created by a solid-propellant rocket engine was considered. By means of simulation, a comparative analysis of the range of a guided aerial bomb equipped (not equipped) with a solid-propellant rocket engine under typical flight conditions of the carrier aircraft during level flight and climb bombing was performed. It was demonstrated that the use of a solid-propellant rocket engine, whose mass is $20 \%$ of the guided aerial bomb's mass, allows to increase the horizontal range of its flight at least twice.
\end{abstract}

\section{Keywords:}

aircraft, climbing, guided aerial bomb, horizontal range, motion trajectory, solidpropellant rocket engine, total thrust impulse

\section{Introduction}

Articulation of the issue. One of the main guided aviation bomb (GAB) development areas is the extension of their combat employment range in order to prevent the damage of GAB aircraft carrier by air defense means covering ground targets (GT). One of the main parameters that characterizes the maximum range of GAB combat employment is the value of the horizontal range, which means the maximum distance from the projection on the ground surface of the GAB release point to the GT.

The extension of the GAB horizontal range is possible due to the following factors:

- maximum use of the aircraft energy potential during aircraft combat employment, by means of aircraft gaining the maximum possible flight speed usually limited by the GAB design, aerodynamic features and its fitting to aircraft,

\footnotetext{
* Corresponding author: State Research Institute of Aviation, Hryhoryia Andriushchenko st. $6 \mathrm{~V}$, Kyiv, UA-01135, Ukraine.Phone: +380685 83 12 33, E-mail: bashynskyid@gmail.com, ORCID 0000-0002-4949-6225.
} 
- GAB energy potential increase by creating jet propulsion on the trajectory of GAB free motion, for example by means of a solid - propellant rocket engine (SPRE), which leads to an increase in GAB speed and range,

- improvement of GAB aerodynamic characteristics by advancing the aerodynamic layout, reducing drag, using an additional wing.

The use of an additional wing with the purpose to increase GAB horizontal flight range has become quite widespread. The additional wing is especially effective when dropping GAB from $5 \mathrm{~km}$ to $10 \mathrm{~km}$ altitude, which ensures $\mathrm{GAB}$ flight at distances exceeding the delivery altitude 5 or more times [1]. But GAB combat employment at such altitudes does not ensure a stealthy attack. If it is necessary to provide a stealth approach of the aircraft to the attack zone, then the most effective GAB maneuver is the flight of the aircraft at extremely low altitudes $(H<200 \mathrm{~m})$ with maximum speed and climb (toss) bombing [2]. When performing such bombing, the use of an additional wing in the GAB design does not provide the expected flight range extension due to the fact that on the lifting leg of GAB trajectory with increased drag, generated by an additional wing, the GAB will decelerate. As a result, the flight speed and altitude, which the GAB will reach at the top of its trajectory, will not significantly extend the flight range. Therefore, it is advisable to consider flight range extension of a GAB using a SPRE.

\section{Analysis of Recent Research and Publication}

The application of jet engines energy, in particular SPRE as a part of GAB, with the purpose to increase its flight range is described in a significant number of publications, for example [3-7], but the known publications do not address the use of SPRE to extend $\mathrm{GAB}$ range during climb bombing. There are also no quantitative characteristics of GAB flight range extension due to the use of SPRE with variable flight parameters of the aircraft during combat employment.

The purpose of the article is to study the possibilities of using SPRE as part of $\mathrm{GAB}$ to increase the horizontal range of its flight during climb bombing.

\section{Presentation of the Main Material}

One of the main tactics used by attack aircraft and front-line bombers when striking ground targets is to fly at the lowest possible altitude with the maximum possible speed, followed by climb (toss) bombing. The purpose of climb bombing is to carry out the attack secretly and increase the horizontal component of the flight range of the destruction means. Such tactics are equally effective when using both unguided drop bombs and GAB. When using GAB for climb bombing, it is necessary to take into account the fact that during such a maneuver there may be no visual contact of the aircraft with the ground target. Therefore, the GAB guidance for climb bombing should be carried out with the systems that do not lock on the ground target before GAB release from the aircraft carrier. Such guidance systems include, for example, a satellite ground target guidance system, whose coordinates are known in advance, or a semi-active laser homing system with ground target trajectory capture, which is illuminated by a ground-based laser target indicator.

Let us consider the schemes of GAB motion in the vertical $O X Y$ plane during level-flight bombing; (Fig. 1) and climb bombing (Fig. 2), where the parameters marked by the " $r$ " index refer to the case of level-flight bombing, and the index " $k$ " 
refer to climb bombing; $B_{\mathrm{h}}, B_{\mathrm{c}}$ are GAB the release points; $C_{\mathrm{h}}, C_{\mathrm{c}}$ are the GAB points of impact; $H_{\mathrm{h}}, H_{\mathrm{c}}$ and $V_{\mathrm{h}}, V_{\mathrm{c}}$ are the aircraft altitude and speed at the time of GAB release; $A_{\mathrm{h}}, A_{\mathrm{c}}$ are the horizontal GAB range, $\Theta$ is the angle of climb at the moment of $\mathrm{GAB}$ release.

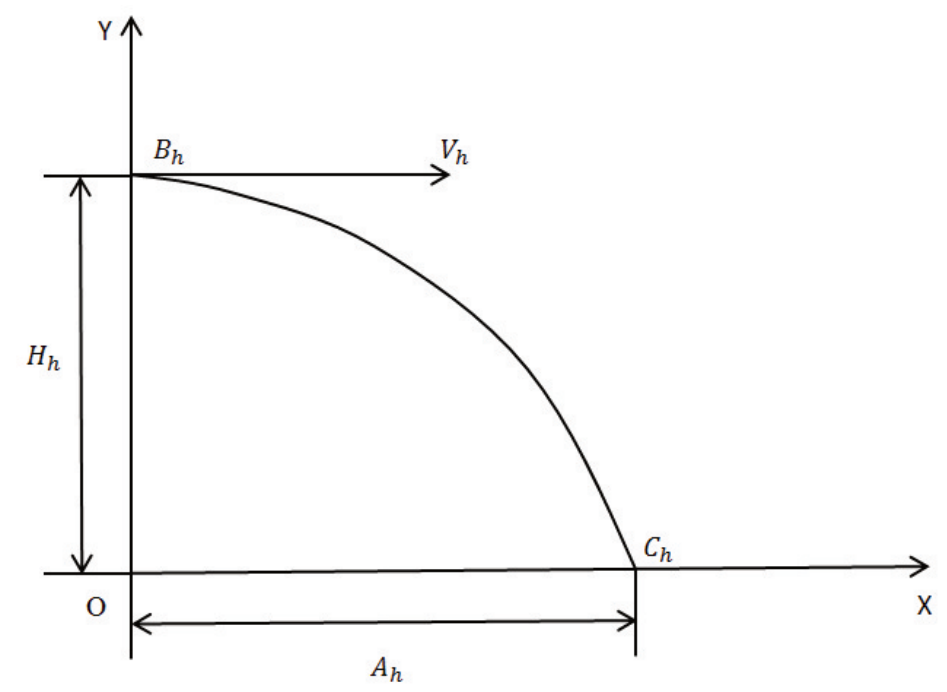

Fig. 1 GAB motion in the vertical plane during level-flight bombing

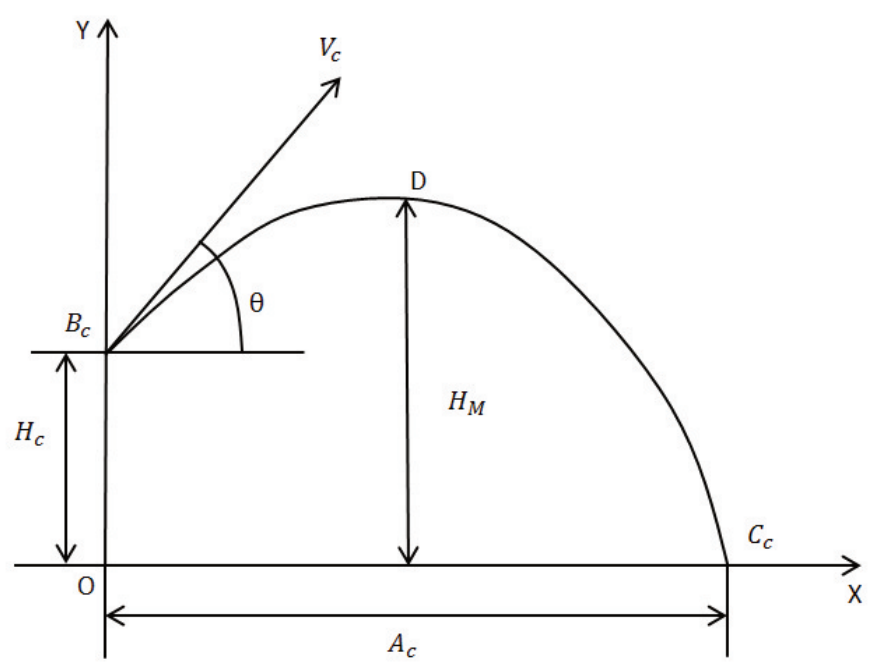

Fig. 2 GAB motion in the vertical plane during climb bombing

For a preliminary analysis of the characteristics of GAB motion on the ballistic trajectory, let us consider its motion without taking into account the air drag and control system operation. The main GAB ballistic parameters are flight time $T_{\mathrm{h}}, T_{\mathrm{c}}$ and horizontal range $A_{\mathrm{h}}, A_{\mathrm{c}}$. 
During level-flight bombing, bomb fall time $T_{\mathrm{h}}$ and horizontal range $A_{\mathrm{h}}$ will be recorded using the following formulas:

$$
\begin{gathered}
T_{\mathrm{h}}=\frac{\sqrt{2 g H_{\mathrm{h}}}}{g} \\
A_{\mathrm{h}}=\frac{V_{\mathrm{h}} \sqrt{2 g H_{\mathrm{h}}}}{g}
\end{gathered}
$$

where $g$ is the acceleration of free fall.

When releasing GAB during climb bombing, GAB trajectory has two characteristic areas. In the first area, in the process of free motion, GAB rises from the release point $B_{\mathrm{c}}$ to the top of the trajectory $D$, where it reaches its maximum altitude $H_{\mathrm{M}}$. In the second area, starting from the point $D$, GAB continues to move and it falls at the point $C_{\mathrm{c}}$. The altitude $H_{\mathrm{M}}$ can be obtained using the formula:

$$
H_{\mathrm{M}}=H_{\mathrm{c}}+\frac{\left(V_{\mathrm{c}} \sin \Theta\right)^{2}}{2 g}
$$

In Eq. (3), value $H_{\mathrm{c}}$ can be obtained:

$$
H_{\mathrm{c}}=H_{\mathrm{c} i}+\frac{V_{\mathrm{c}}^{2}}{n_{\mathrm{ACFT}} g}(1-\cos \Theta)
$$

where $H_{\mathrm{c} i}$ is the aircraft flight altitude at climb initiation; $n_{\mathrm{ACFT}}$ is the aircraft overloading during climb maneuver.

Time of GAB flight $T_{\mathrm{c}}$ during climb bombing can be represented as a sum of elevation time $T_{\mathrm{e}}$ and fall time $T_{\mathrm{f}}$ :

$$
T_{\mathrm{c}}=T_{\mathrm{e}}+T_{\mathrm{f}}
$$

Using Eq. (1) and replacing $H_{\mathrm{h}}$ by parameter $H_{\mathrm{M}}$, which is defined by Eq. (3), we will record an equation for $T_{\mathrm{f}}$ as the following:

$$
T_{\mathrm{f}}=\frac{\sqrt{2 g H_{\mathrm{c}}+\left(V_{\mathrm{c}} \sin \Theta\right)^{2}}}{g}
$$

Then taking into account that $T_{\mathrm{e}}=V_{\mathrm{c}} \sin \Theta / g$, we obtain an equation for $T_{\mathrm{c}}$ as the following:

$$
T_{\mathrm{c}}=\frac{\sqrt{2 g H_{\mathrm{c}}+\left(V_{\mathrm{c}} \sin \Theta\right)^{2}}}{g}+\frac{V_{\mathrm{c}} \sin \Theta}{g}
$$

We will express the horizontal component of GAB speed during climb bombing, as $V_{\mathrm{c}} \cos \Theta$, then, based on Eq. (5), we can write the equation for the horizontal range $A_{\mathrm{c}}$ :

$$
A_{\mathrm{c}}=V_{\mathrm{c}} \cos \Theta \frac{\sqrt{2 g H_{\mathrm{c}}+\left(V_{\mathrm{c}} \sin \Theta\right)^{2}}}{g}+\frac{V_{\mathrm{c}}^{2} \cos \Theta \sin \Theta}{g}
$$

When GAB is released at extremely low altitude, it is possible to assume that $H_{\mathrm{c}} \approx 0$, then Eq. (6) is the following: 


$$
A_{\mathrm{c}}=\frac{2 V_{\mathrm{c}}^{2} \cos \Theta \sin \Theta}{g}
$$

As a result $\cos \Theta \sin \Theta$ in Eq. (7) has maximum value at $\Theta=\pi / 4$, then the maximal horizontal range $A_{\text {max } \_ \text {hr }}$ equals:

$$
A_{\text {max } \_ \text {hr }}=\frac{V_{\mathrm{c}}^{2}}{g}
$$

that is, the most probable climb angle at GAB release at extremely low altitudes is the angle $\Theta=\pi / 4$, and the maximal value of horizontal range $A_{\text {max_hr }}$ depends on root $V_{\mathrm{c}}^{2}$ of aircraft speed at the moment of GAB release during climb bombing.

If $H_{\mathrm{c}} \gg 0$, then the most probable climb angle is $\Theta_{\mathrm{H}}$ and the value of the largest range $A_{\max \_ \text {hr }}$, regardless of wind drag, is defined by the following formulas [2]:

$$
\begin{gathered}
\Theta_{\mathrm{H}}=\arcsin \frac{1}{\sqrt{2\left(1+\frac{g H_{\mathrm{c}}}{V_{\mathrm{c}}^{2}}\right)}} \\
A_{\text {max }_{-} \mathrm{hr}}=\frac{V_{\mathrm{c}}}{g} \sqrt{V_{\mathrm{c}}^{2}+2 g H_{\mathrm{c}}}
\end{gathered}
$$

Analysis of Eqs (2) and (9) shows that at the same speeds and altitudes of GAB release, the value of the horizontal range during climb bombing significantly exceeds the horizontal range value of the level-flight bombing.

In real conditions, due to deceleration caused by air drag, the GAB flight speed will decrease, so the maximum horizontal range values will be significantly lower than calculated in Eqs (6) or (9). If propulsion unit (PU) will speed up GAB $\Delta V$ during its free motion, then such additional speed $\Delta V$ would compensate air drag, which will facilitate the extension of actual flight range. The increase of GAB speed, without taking into account air drag and gravity, can be expressed by the formula:

$$
\Delta V=\frac{I_{\Sigma}}{m_{\mathrm{GAB}}+m_{\mathrm{medPU}}}
$$

where $I_{\Sigma}$ is the total PU propulsive burn; $m_{\mathrm{GAB}}$ is the GAB mass without PU; $m_{\text {medPU }}$ is the medium PU mass while operating.

Solid propellant accelerators, which are solid - propellant rocket engines (SPRE), have become the most widespread PUs for GAB speed acceleration. According to formula (10), the additional speed $\Delta V$ depends proportionally on the total thrust impulse $I_{\Sigma}$, which, in turn, is determined by the energy characteristics and solid propellant weight. When determining the required value $I_{\Sigma}$, it is necessary to take into account the restrictions, namely SPRE mass restrictions in relation to the GAB mass, and restrictions of the $\Delta V$ value.

According to the statistics, the SPRE mass $m_{\mathrm{SPRE}}$ used as GAB rocket accelerators averages $20 \%$ of $m_{\mathrm{GAB}}$ mass [3].

Consider for example the GAB equipped with SPRE, whose layout is shown in Fig. 3. This GAB is an assembly of a drop aircraft bomb FAB-250-M54, aerodynamic control unit BAU-01KT and additional fin assembly [8]. 


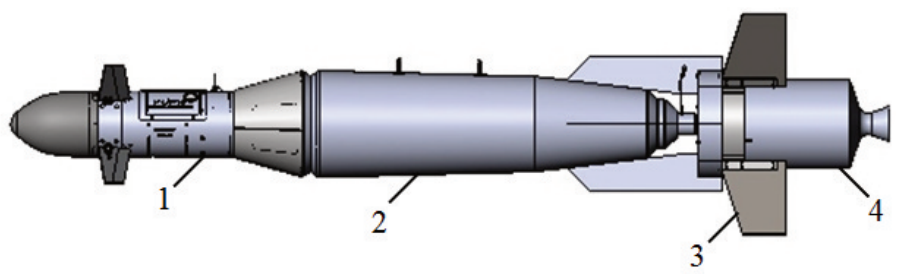

Fig. 3 GAB layout with SPRE: 1 - aerodynamic control unit; 2 - drop aircraft bomb FAB-250-M54; 3 - additional fin assembly; 4 - SPRE

The mass of such GAB is about $270 \mathrm{~kg}$. Then, assuming that the mass of the SPRE will be about $20 \%$ of the GAB mass, we can assume that $m_{\mathrm{SPRE}}=54 \mathrm{~kg}$.

The need to limit the $\Delta V$ value is explained as follows. Most of the existing GAB, as well as GAB depicted in Fig. 3, according to their aerodynamic and strength characteristics are manufactured as subsonic flying objects, whose static and dynamic stability and controllability are within the given calculated limits. In order to prevent the parameters of GAB stability and controllability from exceeding the calculated limits, the additional speed $\Delta V$ should not lead to the GAB supersonic flight.

With a known mass $m_{\mathrm{SPRE}}$, the mass of solid propellant $m_{\mathrm{SP}}$ can be determined by the formula [9]:

$$
m_{\mathrm{SP}}=\frac{m_{\mathrm{SPRE}}}{1+\alpha}
$$

where $\alpha$ is the coefficient of constructive perfection of SPRE.

If the mass of solid propellant $m_{\mathrm{SP}}$ is known, the total thrust $I_{\Sigma}$ is determined by the formula:

$$
I_{\Sigma}=m_{\mathrm{SP}} I_{\mathrm{SI}} \beta
$$

where $I_{\mathrm{SI}}$ is the specific impulse of solid propellant thrust; $\beta$ - the coefficient that takes into account the total thrust losses of SPRE due to the heterogeneity of the propellant combustion process and the nozzle imperfection.

If the thrust $P$ generated by SPRE is constant during the time $t_{\text {comb }}$ of solid propellant combustion, then the equation is fair:

$$
P=\frac{I_{\Sigma}}{t_{\text {comb }}}
$$

To assess the real parameters of the GAB motion, in particular the values of the horizontal range $A_{\mathrm{h}}$ and $A_{\mathrm{c}}$, it is necessary to take into account the braking effect of the incoming air flow, which depends on the aerodynamic characteristics of the GAB, as well as the speed and altitude of its flight.

The most suitable way to obtain real parameters of the GAB motion in the real atmosphere is the method of mathematical simulation. Later on, a mathematical model of the GAB flight was used for simulation, which is an assembly of a drop aircraft bomb FAB-250-M54, aerodynamic control unit BAU-01KT and additional fin assembly [8].

Simulation was carried out for front - line aircraft bombing, performing the combat use of the GAB from the level flight and climb bombing in such typical conditions: 
GAB release height $H_{\mathrm{h}}=500-1500 \mathrm{~m}$; aircraft speed at the moment of GAB release $V_{\mathrm{ACFT}}=750-950 \mathrm{~km} / \mathrm{h}$; aircraft overload during climb bombing $n_{\mathrm{ACFT}}=4$ units; the angle of climb at the moment of GAB release $\Theta=45^{\circ}$. The main results of the simulation are the ballistic motion trajectories of the $\mathrm{GAB}$, which are obtained under different typical conditions of combat use and different maneuvers of the aircraft.

Ballistic motion trajectories of the GAB in the vertical plane during their combat use from a level flight, are presented in Figs 4 and 5.

Fig. 4 shows ballistic trajectories of the GAB at the moment of release from the aircraft, performing level flight with parameters $V_{\mathrm{h}}=850 \mathrm{~km} / \mathrm{h} ; H_{\mathrm{h}}=500 \mathrm{~m}, 1000 \mathrm{~m}$, $1500 \mathrm{~m}$.

Fig. 5 presents ballistic trajectories of the GAB at the moment of release from the aircraft, performing level flight with parameters: $H_{\mathrm{h}}=1000 \mathrm{~m} ; V_{\mathrm{h}}=750 \mathrm{~km} / \mathrm{h}$, $850 \mathrm{~km} / \mathrm{h}, 950 \mathrm{~km} / \mathrm{h}$.

These figures show that for typical bombing conditions from a level flight, the horizontal range of the GAB is $A_{\mathrm{h}}=2500-4500 \mathrm{~m}$. Taking into account the fact that in this case the aircraft approach to the area of GAB release cannot be stealthy and the horizontal range is not more than $4500 \mathrm{~m}$, we can conclude that the aircraft during the combat use of the GAB from a level flight is in the engagement zone of the enemy's air defense, so the safety requirements for the aircraft regarding air defense are not fulfilled.

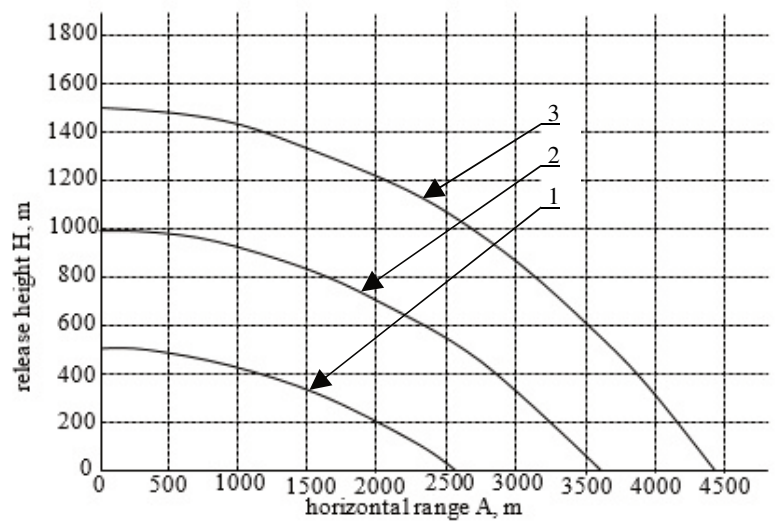

Fig. 4 Ballistic trajectories of the GAB at the moment of release from an aircraft, performing a level flight at the speed $V_{\mathrm{h}}=850 \mathrm{~km} / \mathrm{h}$ at altitudes: $1-H_{\mathrm{h}}=500 \mathrm{~m}$;

$$
2-H_{\mathrm{h}}=1000 \mathrm{~m} ; 3-H_{\mathrm{h}}=1500 \mathrm{~m}
$$

A completely different picture is observed in the combat use of GAB during climb bombing.

The results of mathematical simulation of the GAB motion in the vertical plane during climb bombing at the angle $\Theta=45^{\circ}$, the value of which is close to the most favorable, are shown in Figs 6 and 7.

Fig. 6 shows the ballistic trajectories of the GAB motion during climb bombing with the parameters of the aircraft flight $V_{\mathrm{c}}=850 \mathrm{~km} / \mathrm{h} ; H_{\mathrm{c}}=500 \mathrm{~m}, 1000 \mathrm{~m}, 1500 \mathrm{~m}$.

Fig. 7 shows the ballistic trajectories of the GAB motion during climb bombing with the parameters of the aircraft flight: $H_{\mathrm{c}}=1000 \mathrm{~m} ; V_{\mathrm{c}}=750 \mathrm{~km} / \mathrm{h}, 850 \mathrm{~km} / \mathrm{h}$, $950 \mathrm{~km} / \mathrm{h}$. 


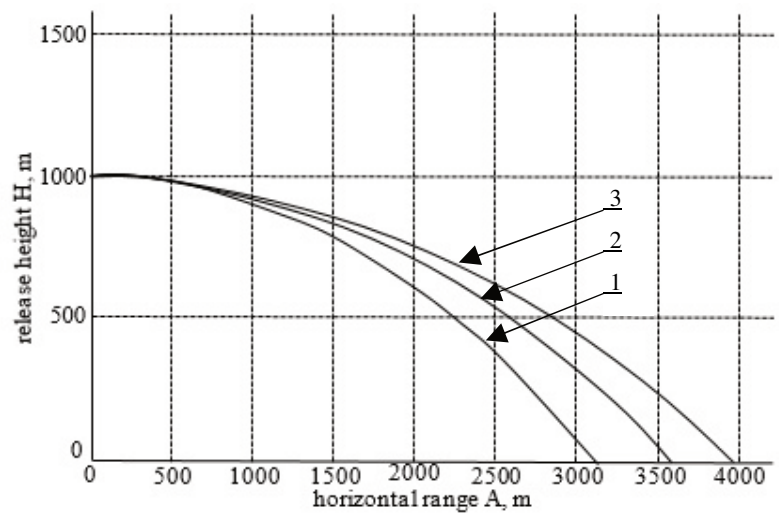

Fig. 5 Ballistic trajectories of the GAB at the moment of release from the aircraft in level flight at the altitude $H_{\mathrm{h}}=1000 \mathrm{~m}$ at speeds: $1-V_{\mathrm{h}}=750 \mathrm{~km} / \mathrm{h}$;

$2-V_{\mathrm{h}}=850 \mathrm{~km} / \mathrm{h} ; 3-V_{\mathrm{h}}=950 \mathrm{~km} / \mathrm{h}$

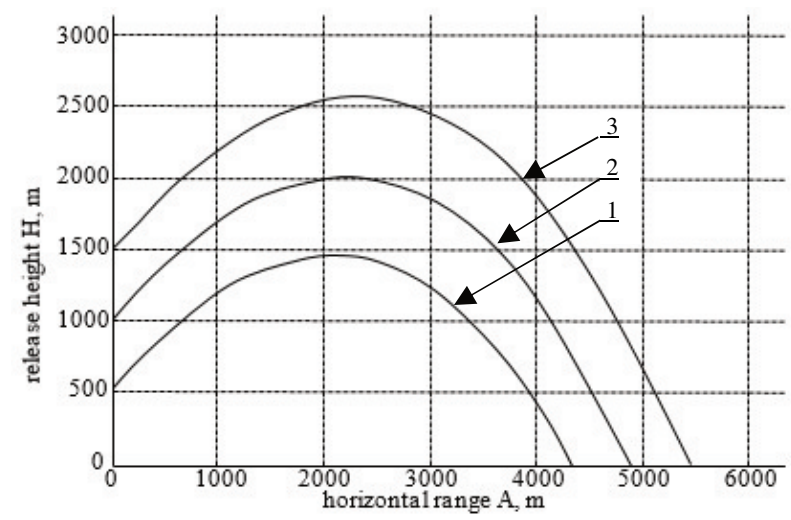

Fig. 6 Ballistic trajectories of the GAB motion during climb bombing at $V_{\mathrm{c}}=850 \mathrm{~km} / \mathrm{h}$ and release altitudes: $1-H_{\mathrm{c}}=500 \mathrm{~m} ; 2-H_{\mathrm{c}}=1000 \mathrm{~m} ; 3-H_{\mathrm{c}}=1500 \mathrm{~m}$

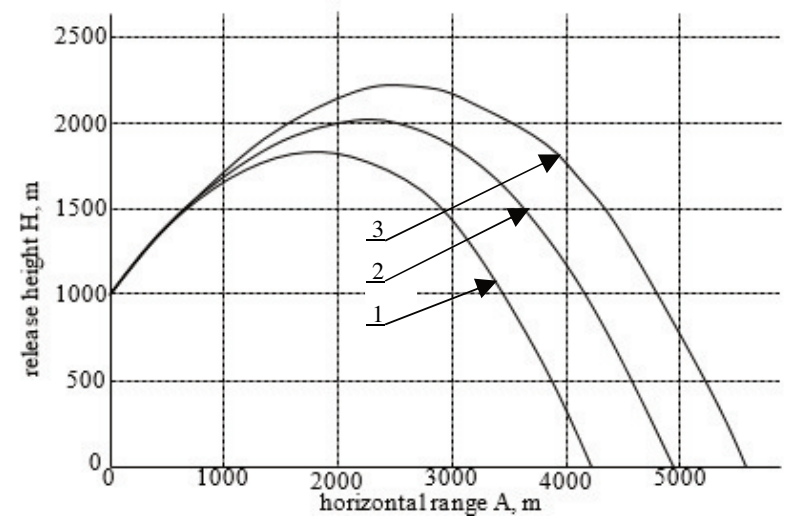

Fig. 7 Ballistic trajectories of the GAB motion during climb bombing at $H_{\mathrm{c}}=1000 \mathrm{~m}$ and aircraft flight parameters: $1-V_{\mathrm{c}}=750 \mathrm{~km} / \mathrm{h} ; 2-V_{\mathrm{c}}=850 \mathrm{~km} / \mathrm{h} ; 3-V_{\mathrm{c}}=950 \mathrm{~km} / \mathrm{h}$ 
The simulation results which are presented in Figs 6 and 7 show that under typical conditions of climb bombing, the horizontal range of the GAB is slightly exceeded compared with bombing from a level flight and amounts to $4200-5600 \mathrm{~m}$ (exceeds by 1.3-1.4 or 30-40\%). If we take into account that during climb bombing it is possible to implement a covert approach of the aircraft to the area of the GAB use, as well as that the climb bombing maneuver is also a missile evasive maneuver, we can make the following conclusion. During combat use of the GAB for climb bombing, the aircraft may not be hit by short-range air defense systems, such as portable air defense systems (PADS) and air defense missile systems (ADMS) of the "Strela-10M" type, which have a maximum hitting range of no more than $5 \mathrm{~km}$. Further increase in the flight range of the GAB is possible if the SPRE is used.

For mathematical simulation of GAB flight with the SPRE, the following initial data were accepted: $m_{\mathrm{SPRE}}=54 \mathrm{~kg}(20 \%$ of the GAB mass $) \alpha=0.5 ; \beta=0.9$; $I_{\mathrm{SI}}=2200 \mathrm{~N} \mathrm{~s} / \mathrm{kg}$, and using formulas (11)-(13) the parameters of the SPRE were determined: $m_{\mathrm{SP}}=36 \mathrm{~kg} ; I_{\Sigma}=71280 \mathrm{~N} \mathrm{~s} ; t_{\mathrm{comb}}=10 \mathrm{~s} ; P=7128 \mathrm{~N}$.

The simulation was performed for climb bombing in the following typical conditions: the altitude of the GAB release with SPRE was calculated by formula (4) at $H_{\mathrm{c} i}=200 \mathrm{~m}$; the speed of the aircraft at the moment of the GAB release: $V_{\mathrm{c}}=750 \mathrm{~km} / \mathrm{h}, \quad 850 \mathrm{~km} / \mathrm{h}, \quad 950 \mathrm{~km} / \mathrm{h}$; aircraft overload during climb bombing $n_{\mathrm{ACFT}}=4$ units; the angle of climb at the moment of the GAB release $\Theta=45^{\circ}$.

The simulation results of the GAB motion with SPRE in the form of its ballistic trajectories in the vertical plane are shown in Fig. 8.

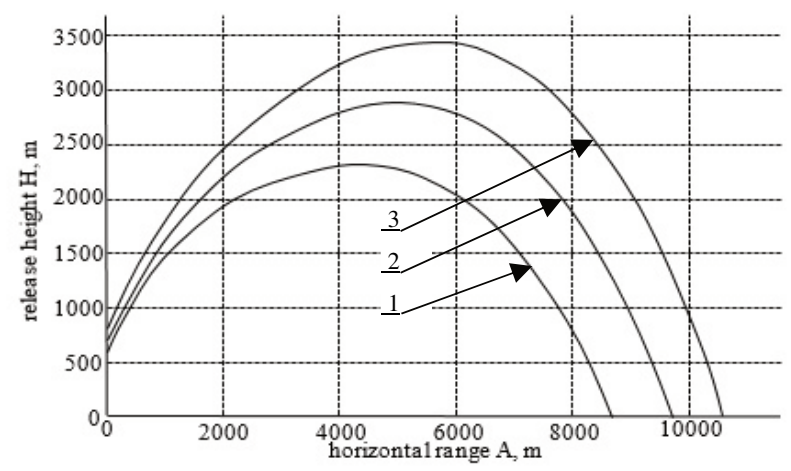

Fig. 8 Ballistic trajectories of the GAB motion with SPRE in the vertical plane:

$1-V_{\mathrm{c}}=750 \mathrm{~km} / \mathrm{h} ; 2-V_{\mathrm{c}}=850 \mathrm{~km} / \mathrm{h} ; 3-V_{\mathrm{c}}=950 \mathrm{~km} / \mathrm{h}$

These results prove that the use of GAB equipped with SPRE during climb bombing allows increasing the horizontal range to $8500-10500 \mathrm{~m}$, which is almost twice as much as the horizontal range of GAB which is not equipped with SPRE.

Fig. 8 shows ballistic trajectories of the GAB motion, i.e. trajectories obtained without taking into account the control system activities. The control system allows to change significantly the trajectory of the GAB motion relative to the ballistic one. Simulation of the GAB motion with the operating control system allows to obtain parameters of the maximum and minimum reach of $\mathrm{GAB}$, i.e. maximum and minimum horizontal range to GT, within which the GAB has the possibility of hitting GT under given initial conditions of combat use. To obtain the maximum reach of the GAB, the simulation of its motion was performed with the maximum positive deviation of the 
rudders $\left(+\delta_{\max }\right)$ in the vertical control channel, and to obtain the minimum reach of the $\mathrm{GAB}$, the simulation was performed with the maximum negative deviation of the rudders $\left(-\delta_{\max }\right)$ in the same channel. The simulation results of the GAB equipped with SPRE with above mentioned parameters, at $H_{\mathrm{c}}=800 \mathrm{~m}, V_{\mathrm{c}}=950 \mathrm{~km} / \mathrm{h}, \Theta=45^{\circ}$, as well as at the beginning of the control system operation at the highest point of the GAB's trajectory are presented in Fig. 9.

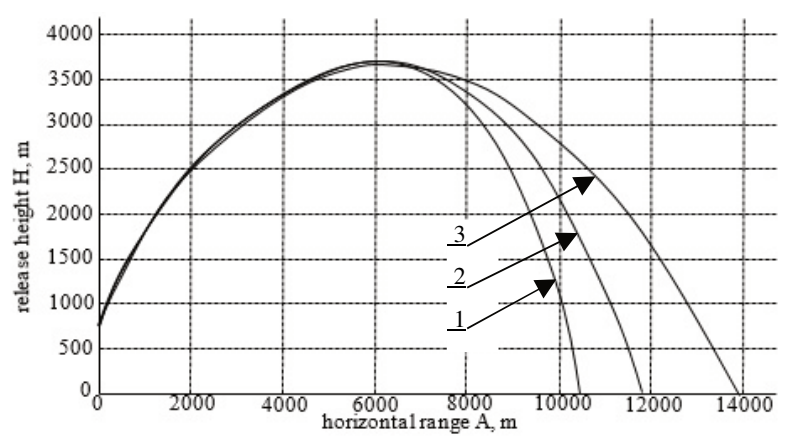

Fig. 9 The motion trajectories of GAB equipped with SPRE in the vertical plane:

1 - ballistic trajectory; 2 - the trajectory of maximum reach $\left(+\delta_{\max }\right)$;

3 - the trajectory of the minimum reach $\left(-\delta_{\max }\right)$

The simulation results of the GAB equipped with SPRE with the operating control system show that during climb bombing the maximum horizontal flight range of the GAB (its maximum reach) amounts to $13.9 \mathrm{~km}$, the minimum range $-10.4 \mathrm{~km}$, and the reach zone (the difference between the maximum and minimum reach), in which the ground target can be defeated is $3.5 \mathrm{~km}$.

This means that, taking into account the possibility of covert approach to the combat area and further climb bombing with simultaneous execution of a missile evasive maneuver by the aircraft [Article 2], the horizontal flight range of the GAB equipped with SPRE ensures avoiding of aircraft hitting by short-range air defense systems, such as air defense missile system "Strela-10M" and its modifications, "Osa", "Tor-M", and short-range anti-aircraft missile and gun complex "Pantsir-S" and their analogues $[10,11]$.

As a result of the simulation, graphic dependencies of the Mach number $M$ on the flight time $t$ for GAB equipped with SPRE, under the same combat use conditions, and accepted for calculation of the flight trajectory of GAB equipped with SPRE in the vertical plane were also obtained (see Fig. 8). Graphic dependencies of the Mach number $M$ on the flight time $t$ for a SPRE-type GAB are shown in Fig. 10.

The obtained graphs of the dependence of the Mach flight number of the GAB equipped with SPRE on time $t$ show that at the set and defined parameters of GAB and $\mathrm{SPRE}-m_{\mathrm{GAB}}=270 \mathrm{~kg} ; m_{\mathrm{SPRE}}=54 \mathrm{~kg}(20 \%$ of the $\mathrm{GAB}$ mass $) ; m_{\mathrm{SP}}=36 \mathrm{~kg}$; $I_{\Sigma}=71280 \mathrm{~N} \mathrm{~s} ; t_{\mathrm{comb}}=10 \mathrm{~s} ; P=7128 \mathrm{~N}$, as well as under given typical conditions of combat use for climb bombing and the leading of the aircraft into climb bombing at extremely low altitudes $(H<200 \mathrm{~m})$, when turning on SPRE (thrust start) not earlier than $6 \mathrm{~s}$ after its separation from the aircraft, the maximum value of the Mach number reaches $0.9-0.96$. This means that the GAB flight speed on the trajectory of free motion remains subsonic, at which its static and dynamic stability and controllability are changing within the given calculated limits during the whole time of its flight. 


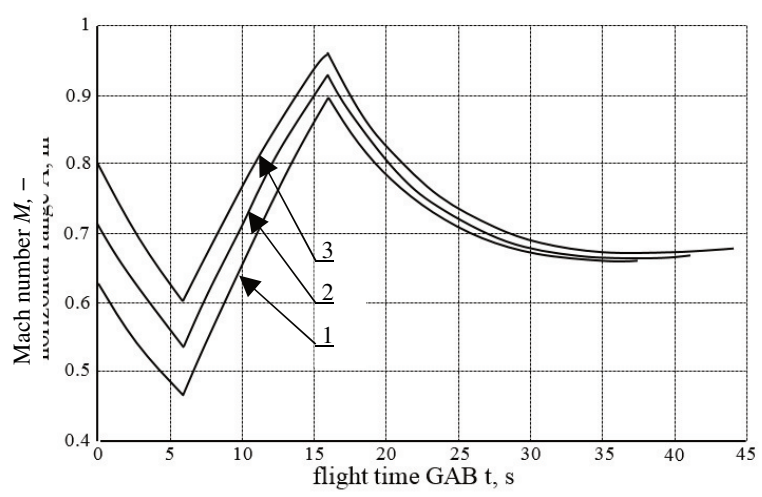

Fig. 10 Graphs of the dependence of the Mach flight number of GAB, equipped with $S P R E$, on time $t: 1-V_{\mathrm{c}}=750 \mathrm{~km} / \mathrm{h} ; 2-V_{\mathrm{c}}=850 \mathrm{~km} / \mathrm{h} ; 3-V_{\mathrm{c}}=950 \mathrm{~km} / \mathrm{h}$

\section{Conclusions}

The simulation results showed that under typical conditions of climb bombing the GAB horizontal range is extended 1.3-1.4 times or by 30-40\% compared with level flight bombing, and constitutes $4200-5600 \mathrm{~m}$. If we take into account that during the climb bombing it is possible to implement a covert approach of the aircraft to the area of GAB release, as well as that the maneuver of climb bombing is also a missile evasive maneuver, then during the GAB combat use it is possible that the aircraft may not be hit by air defense systems covering ground targets, such as Man-Portable Short Range Air Defence System "Igla-S" and Air Defence Missile System "Strela-10M", which have a maximum hitting range of no more than 5-6 km.

Equipping the GAB with a solid-propellant rocket engine, the mass of which is $20 \%$ of the GAB mass, during the climb bombing at the moment of missile evasive maneuver, in controlled flight mode allows to obtain maximum range exceeding $13.5 \mathrm{~km}$. Such a GAB flight range ensures that the aircraft cannot be hit by short-range air defense systems covering the ground target, in particular, such as "Strela-10M" ADMS and its modifications, "Osa", "Tor-M" and their analogues, as well as shortrange anti-aircraft missile and gun complex "Pantsir-S" and its modifications.

The start time of thrust and the operating time of the solid-propellant rocket engine provide subsonic GAB flight on the trajectory of its free motion, when the maximum value of the Mach number does not exceed the values of $M=0.9-0.96$. This means that the static and dynamic stability and controllability of the GAB equipped with SPRE are changing within given calculated limits throughout its flight time.

\section{References}

[1] FOMYCHEVA, O.A. Improved Ballistic Capability of Guided Aerial Bombs. News of TulGU. Technical Sciences (in Russian). 2016, 4, pp. 98-105. ISSN 2071-6168.

[2] KYRYLLOV, V.Y. Bombing (in Russian). Moscow: Military Publishing, 1960.

[3] SEMENOV, S.S., V.N. KHARCHEV and A.Y. YOFFYN. Assessment of the Technical Level of Weapons and Military Equipment (in Russian). Moscow: Radio and Communications, 2004. ISBN 978-5-256-01671-5. 
[4] AHAFONOV, Y.M., O.M. ZHARYK, Y.M. OSYPOV and Y.A. TKACHENKO. The Ways of Aviation Munition Modernization Substantiation (in Russian). Systems of Arms and Military Equipment, 2017, 2(50), pp. 50-52. ISSN 1997-9568.

[5] VETROV, V.V., V.A. DUNAEV, E.M. KOSTIANOI and V.V. MOROZOV Implementation of the Near-Zone Ballistic Efficiency Concept (in Russian). Basic Research, 2012, 11(2), pp. 377-382. ISSN 1812-7339.

[6] SEMENOV, S. Major R\&D Activities to Improve Guided Aerial Bombs (in Russian). Foreign Military Review, 2016, 11, pp. 63-67. ISSN 0134-921X.

[7] KARPOV, S.Y., YU.S. KUCHERENKO, YU.N. LEVCHENKO, et al. Controlled Aviation Bomb (in Russian). Patent RF No. RU2391624. Available from: http://www.freepatent.ru/patents/2391624

[8] KRAVCHUK, I.S. and V.V. TARANENKO. Realization of Proportional SelfHoming of the Corrected Aerial Bomb According to the Information of the Satellite Navigation System (in Ukrainian). Science and Technology of the Air Force of Ukraine, 2019, 3(36), pp. 73-78. DOI 10.30748/nitps.2019.36.08.

[9] ARKHANHELSKYI, Y.Y., P.P. AFANASEV and E.H. BOLOTOV. Design of Surface-to-Air Guided Missiles (in Russian). Moscow: MAI, 2001. ISBN 978-57035-2335-4.

[10] VASYLYN, N.IA. and A.A. HURYNOVYCH. Air-Defence Systems (in Russian). Minsk: Popury, 2002. ISBN 978-985-438-681-2.

[11] FYMUSHKYN, F. and V. SLUHYN. Air-Defence Systems Short-Range "PantirC1-0" with Optoelectronic Guidance System (in Russian). Military Parade Journal, 2004, 63(03), pp 12-14. ISSN 1029-4678. 